\title{
POLLEN-TUBE COMPETITION AND MALE FITNESS IN HIBISCUS MOSCHEUTOS
}

\author{
Allison A. SNOW ${ }^{1}$ AND Timothy P. Spira ${ }^{2}$ \\ ${ }^{1}$ Department of Plant Biology, Ohio State University, 1735 Neil Avenue, Columbus, Ohio 43210-1293, and \\ University of Michigan Biological Station, Pellston, Michigan 49769 \\ E-mail: snow.1@osu.edu \\ ${ }^{2}$ Department of Biological Sciences, Clemson University, Clemson, South Carolina 29634-1903 \\ E-mail: Tim_Spira@quickmail.clemson.edu
}

\begin{abstract}
The stigmas of animal-pollinated flowers often capture more pollen than is needed to fertilize all available ovules, and mixed-donor pollen loads are probably common. When this is the case, variation in average pollen-tube growth rates can potentially affect the number of seeds sired by a given plant. Despite considerable interest in effects of postpollination processes on male fitness, little is known about the extent of variation in pollen performance among plants from natural populations. To examine this question in Hibiscus moscheutos (rose mallow), we conducted mixed-donor hand-pollination experiments with 39 pollen donors bearing distinctive isozyme markers. Pairs of competing donors were compared on sets of 11 to 15 recipient plants per pair. These donors often differed in the proportions of seeds they sired, with the maximum deviation from an expected ratio of 50:50 being 68:32. Furthermore, three intensively studied plants exhibited consistent trends in relative pollen performance when each was tested against (1) the same three competitors, and (2) groups of 14 competitors chosen at random from the study population. In a separate experiment, we investigated the effects of salinity stress and high soil nutrients on pollen performance. These environmental factors had anticipated effects on leaf production, flower production, and petal length, but style length and (most importantly) the number of seeds sired relative to a standard pollen donor were not affected. In summary, this study provides the strongest evidence to date that pollen-tube competitive ability varies among coexisting plants and may be an important component of male fitness in plants.
\end{abstract}

Key words.-Environmental stress, gametophytic selection, genetic marker, male fitness, nonrandom fertilization, paternity, pollen-tube competition, pollination.

Received August 23, $1995 . \quad$ Accepted March 22, 1996.

Sperm competition in animals is influenced by well-documented behavioral, morphological, and physiological traits that affect the success of an individual's sperm after copulation (Smith 1994; Gomendio and Roldan 1993). In flowering plants, an analogous process occurs when the population of germinating pollen grains on a flower's stigma exceeds the number of unfertilized ovules within the ovary. Stigmas of animal-pollinated flowers can receive large doses of pollen from single pollinator visits (or multiple visits in quick succession), such that variation in growth rates of the haploid pollen tubes leads to strong competition for available ovules (Mulcahy 1979). As yet, however, it is not known whether pollen performance differs among plants in the same natural population, or whether such variation affects realized male reproductive success (Stephenson and Bertin 1983; Snow 1986; Snow and Lewis 1993; Snow 1994).

Pollinators often deposit mixtures of "surplus" pollen from several individuals onto receptive stigmas, thereby setting the stage for nonrandom fertilization due to variation in pollen-tube growth rates (reviewed in Snow 1994). Handpollination experiments have shown that pollen-tube competition has the potential to affect mating patterns by (1) inhibiting interspecific crosses between close relatives (Carney et al. 1994; Rieseberg et al. 1995), (2) discriminating against self-pollen as opposed to outcross pollen (e.g., Aizen et al. 1990; Cruzan and Barrett 1993; but see Johnston 1993; Snow and Spira 1993), and (3) limiting the success of pollen from near neighbors (Waser and Price 1991). In some species, pollen competitive ability appears to be influenced by interactions between donors and recipients (e.g., Johnston 1993). In addition, plants that are stressed by herbivore damage or

1 Corresponding author. nutrient deficiency may produce pollen that is less competitive than that from unstressed plants (e.g., Young and Stanton 1990; Lau and Stephenson 1993; Quesada et al. 1995). Notwithstanding evidence for these genetic and environmental effects on pollen performance, it is possible that pollen competitive ability also differs among coexisting individuals.

We investigated this question using plants from a natural population of Hibiscus moscheutos (rose mallow), a herbaceous perennial that occurs in brackish and freshwater marshes of the southeastern United States. The species is selfcompatible, but spatial separation of anthers and stigmas prevents the flowers from setting fruit in the absence of pollinators (Spira 1989; Snow and Spira 1991b). At our study sites in Maryland, the showy, creamy-white flowers were visited frequently by both bumblebees and a specialist anthophorid bee, Ptilothrix bombiformis, and outcrossing rates were estimated to be about $64 \%$ (Snow et al. 1995). Bees often delivered surplus pollen to the stigmas by midmorning on the first day of anthesis, resulting in strong competition among pollen tubes as they traversed the 5 to $6 \mathrm{~cm}$ style (Spira et al. 1992, 1996). On average, stigmas accumulated about 10 to 15 pollen grains per ovule by late afternoon.

In a previous paper, we demonstrated that pollen donors differed in average pollen-tube growth rates when compared on an array of maternal plants (Snow and Spira 1991b). These results were intriguing, but a more reliable way to evaluate the genetic consequences of pollen-tube competition is to use genetic markers to demonstrate variation in siring success. The present study was undertaken in order to (1) measure variation in the proportion of seeds sired by competing donors, (2) determine whether observed differences among three donors were consistent when these donors were compared against different groups of competitors, and (3) test for effects of environmental conditions on pollen performance. 


\section{Materials and Methods}

\section{Competition among Donors}

Rootstock cuttings from more than 50 plants were collected from our Mill Swamp study population in Edgewater, Maryland, and cultivated outdoors. This species does not spread vegetatively; thus, genetically distinct individuals were easily distinguished. Plants were maintained in $20-\mathrm{L}$ pots and were screened for electrophoretic markers at the GPI locus, which has three alleles (glucose-6-phosphate isomerase; see Methods in Snow and Spira 1991b). To assess pollen competitive ability, flowers that were bagged as buds were hand-pollinated with 50:50 mixtures of pollen from one of three "standard" donors and one of 36 "tester" donors (each standard donor was compared with 14 testers). The standards and testers were chosen haphazardly except that each had distinctive Mendelian isozyme markers to allow paternity analysis: standard donors were homozygous for an allele of $G P I$ that was absent in both the tester donors and recipient plants. Three of the tester donors were used with all three standards (see Fig. 1), but otherwise no testers were used with more than one standard. Nine of the tester crosses involving standard 3 were conducted in 1992 at an outdoor field garden in Maryland; in 1993, the plants were moved to a field garden at Clemson University, where all other hand-pollinations were performed.

Two-donor pollinations were accomplished by coating two of the five stigmas on a flower with pollen from a standard donor and two other stigmas with pollen from a tester donor, for a total of approximately 1600 grains per flower (see Snow and Spira 1991b; order of pollen applications was assigned at random). Fruits typically contain 100 to 120 seeds; thus, on average only about one out of 16 pollen grains was able to sire a seed. Pollen doses from the two competing donors were assumed to be equal because the sizes of the four stigmas were visually indistinguishable. We did not attempt to mix pollen from the two sources prior to application, as advocated by Mitchell and Marshall (1995), because the pollen grains are sticky and tend to clump together, making it difficult to achieve equal mixtures. Thus, pollen from the two donors did not have the opportunity to interact on the surface of the stigma, although their pollen tubes converged about 1 $\mathrm{cm}$ below the stigma at the base of the stylar branches (Snow and Spira 1991b).

Each comparison between a given standard and tester represents data from hand-pollinations on 11 to 15 randomly chosen recipient plants (one fruit per plant; many recipients were also used as pollen donors, but none were self-pollinated). This design was adopted in order to characterize average pollen competitive ability across an array of maternal plants, without attempting to quantifying possible donor-byrecipient interactions or to use the same set of recipients with all pairs of donors. An equal number of newly germinated seeds from the 11 to 15 fruits was scored electrophoretically, for a total of 130 to 150 seeds from each pair of donors and more than 4000 seeds in the entire experiment.

Previous experiments revealed no consistent differences among donors in percent pollen germination (Snow and Spira 1992) or the number of seeds sired following single-donor pollinations (unpubl. data); thus, we interpreted deviations from 50:50 in the proportion of seeds sired by pairs of donors as products of variation in pollen competitive ability. Other causes of nonrandom paternity were unlikely because few embryos abort (Snow and Spira 1991b) and seed germination was greater than $95 \%$.

\section{Environmental Effects on Pollen Competitive Ability}

We tested for effects of salt stress and high soil fertility on pollen competitive ability by cultivating plants from the Mill Swamp population under different conditions in a greenhouse. The salinity treatment (described below) was representative of conditions in brackish marshes along Chesapeake Bay where $H$. moscheutos survives and reproduces but is somewhat stunted (Cahoon and Stephenson 1986). The high nutrient treatment was not intended to represent realistic levels of soil fertility, but rather to serve as a contrasting environment.

Twenty-seven potted plants were randomly assigned to one of three environmental treatments: control, salt stress, or nutrient addition. During the previous growing season, these plants were grown in standard potting soil amended with slow-release fertilizer (Osmocote) and then overwintered outdoors. For the present experiment, no additional fertilizer was applied to plants in the control or salt stress treatments. All plants were subirrigated by placing them in plastic pools in a greenhouse and maintaining a constant water depth of 10 $\mathrm{cm}$. Treatments began 4 to $6 \mathrm{wk}$ prior to flowering, before flower buds were visible. For the salt stress treatment, pool water was maintained at $1.0 \% \mathrm{NaCl}$ (salt was added gradually during the first week), and each pot was watered from above with $250 \mathrm{ml}$ of this solution daily. Control and fertilized plants were subirrigated with fresh water and received 250 $\mathrm{ml}$ of fresh water or the recommended dilution of MiracleGro (a commercial fertilizer; $15 \mathrm{~N}: 30 \mathrm{P}: 15 \mathrm{~K}$ ) daily. We did not attempt to quantify soil salinity or nutrient levels but instead relied on the plants' responses to indicate whether these treatments inhibited or stimulated their growth as expected.

To examine treatment effects on plant development, we calculated the average number of new leaves and flowers produced on two randomly selected shoots per plant $(N=9$ after averaging data from the two shoots). Petal and style lengths from the first two flowers on each plant were also averaged. Pollen competitive ability was assessed in a twodonor hand-pollination experiment in which each plant's pollen competed with pollen from the same standard donor (same procedure as described above), which was grown under the same conditions as the control plants. Pollen from each experimental plant was used in competition with the standard donor on one flower of a control plant, for a total of nine fruits from each experimental treatment (none of the control plants was selfed). We scored approximately 23 seeds from each fruit for the GPI isozyme marker to determine the proportion of seeds sired by experimental donors (203-214 seeds per treatment). A separate set of crosses showed that the environmental treatments had no effect on the number of seeds per fruit following single-donor hand-pollinations on nonstressed recipient plants (one-way analysis of variance [ANOVA]; $N=24$; data not shown). 


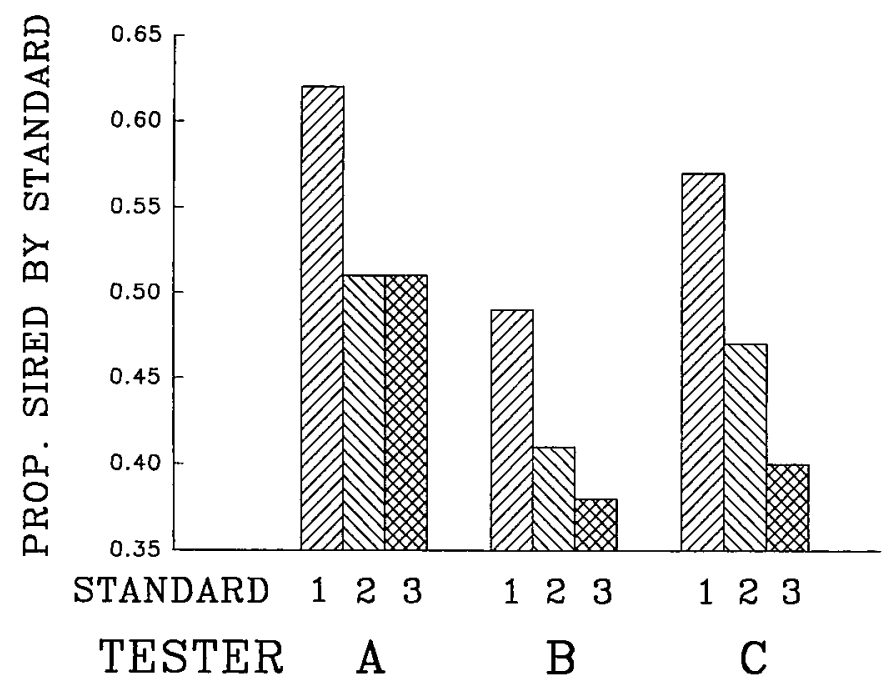

FIG. 1. Proportion of seeds sired by three standard donors $(1,2$, 3) competing with three tester donors (A, B, C); 130 to 150 seeds were scored from each pair of donors. The main effects of tester and standard donors were both significant at $P<0.001$, and the interaction between them was not significant $(P=0.98$; ANOVA, see text).

\section{RESULTS}

\section{Competition among Donors}

When the pollen competitive ability of the three standard donors was compared with that of the same three testers, significant differences in paternal success were found in each group (Fig. 1). Standard 1 sired more seeds than standards 2 or 3 , regardless of which tester donor was used. Likewise, tester A generally sired the fewest seeds, and tester B sired the most, independent of which standard was used. A categorical maximum-likelihood ANOVA (SAS 1994) showed that the main effects of tester and standard donors were significant at $P<0.001$. The interaction between testers and donors was not significant $(P=0.98)$, indicating that the performance of each pollen donor was not strongly influenced by the identity of its competitor.

To further explore variation in pollen competitive ability, pollen from each of the three standard donors was also used in competition with 14 testers. In these crosses, the greatest deviation from the random expectation of 50:50 was 68:32, as shown in Figure 2. Despite variation among the 14 testers in each group, it is clear that on average standard 1 sired more seeds than did standards 2 or $3(59 \%$ versus $43 \%$ and $43 \%$, respectively). Differences among standard donors in the mean proportion of seeds sired were significant at $P<$ 0.001 (one-way ANOVA using arcsine-transformed percentages; $N=14$ testers per standard). Thus, these crosses show that standard 1 is superior to the other two standard donors when compared against randomly selected competing testers. If these testers are representative of the population as a whole, our data suggest that some plants consistently sire more seeds than others when pollen-tube competition is prevalent.

\section{Environmental Effects on Pollen Performance}

The salinity and fertilization treatments had no detectable effects on pollen competitive ability. Brackish conditions re-

\section{STANDARD DONOR 1}

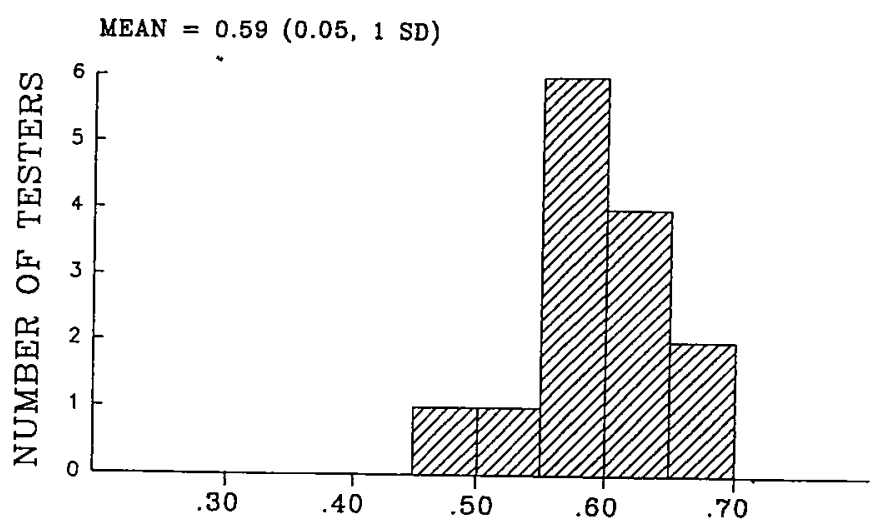

STANDARD DONOR 2

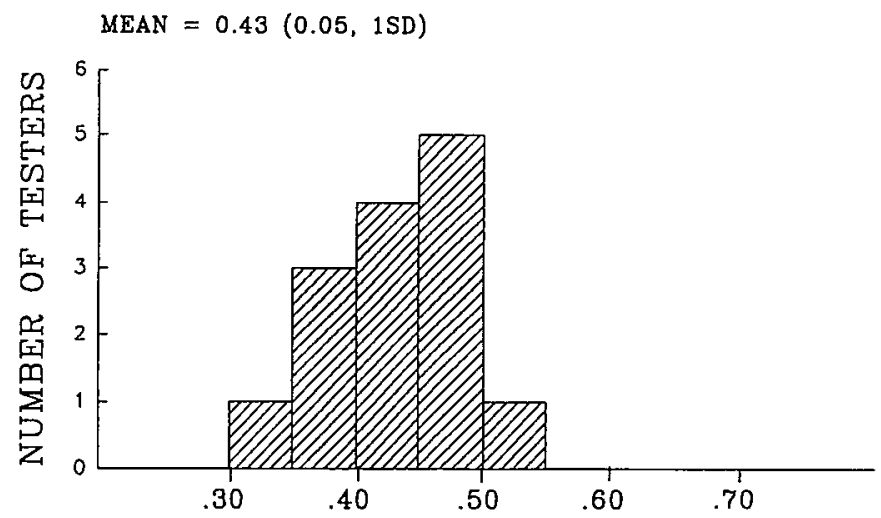

\section{STANDARD DONOR 3}

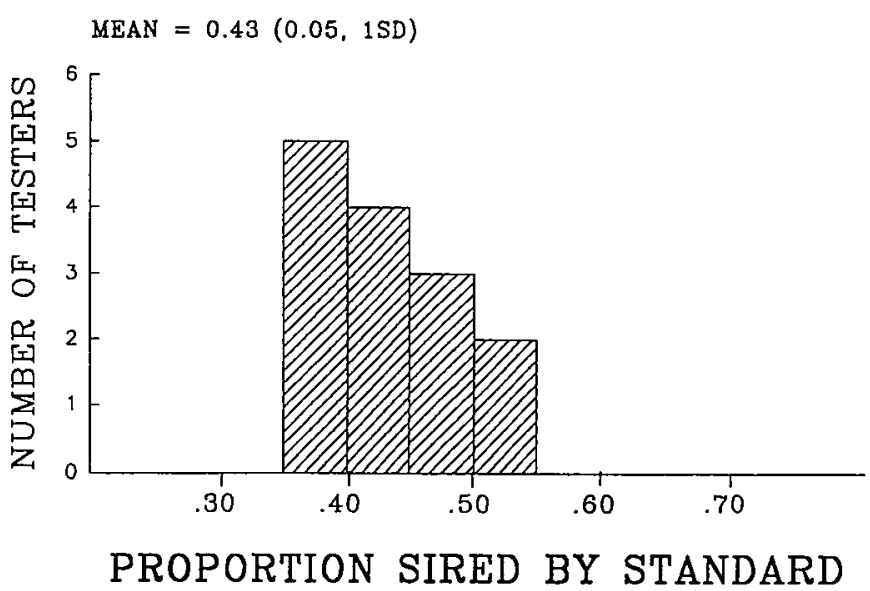

FIG. 2. Frequencies of the proportions of seeds sired by each standard pollen donor when its pollen competed with pollen from 14 tester pollen donors. The range of variation in percent seeds sired relative to the tester donors was $49 \%$ to $68 \%$ for standard $1,33 \%$ to $51 \%$ for standard 2 , and $38 \%$ to $54 \%$ for standard 3 . Differences in the mean percent sired by each standard donor were significant at $P<0.001$ (see text).

sulted in reduced vegetative growth, fewer flowers, and smaller petals as compared with the control treatment, but no change occurred in style length or paternal success following mixed-donor pollinations (Table 1). The high nutrient 
TABLE 1. Environmental effects on plant development and pollen competitive ability. Means with standard deviations in parentheses; $N=9$ unless otherwise noted. Means with different superscripts were significantly different at $P<0.05$ (Tukey tests). Differences in the proportion of seeds sired by plants in each experimental treatment were not significant ( $G$-test).

\begin{tabular}{lccc}
\hline \hline & \multicolumn{3}{c}{ Environmental conditions } \\
\cline { 2 - 4 } & SALT & CONTROL & NUTRIENTS \\
\hline Number of new leaves & $4.7^{\mathrm{a}}$ & $6.4^{\mathrm{b}}$ & $7.2^{\mathrm{b}}$ \\
per shoot & $(0.9)$ & $(0.9)$ & $(1.3)$ \\
Number of flowers & $5.1^{\mathrm{a}}$ & $8.0^{\mathrm{b}}$ & $10.2^{\mathrm{b}}$ \\
per shoot & $(0.6)$ & $(2.1)$ & $(2.4)$ \\
Petal length (mm) & $79^{\mathrm{a}}$ & $90^{\mathrm{b}}$ & $98^{\mathrm{c}}$ \\
& $(8)$ & $(8)$ & $(9)$ \\
Style length (mm) & $49^{\mathrm{a}}$ & $50^{\mathrm{a}}$ & $50^{\mathrm{a}}$ \\
& $(4)$ & $(5)$ & $(2)$ \\
Proportion of seeds sired & $0.53^{\mathrm{a}}$ & $0.47^{\mathrm{a}}$ & $0.52^{\mathrm{a}}$ \\
relative to the & $(N=214)$ & $(N=207)$ & $(N=203)$ \\
standard donor & & & \\
\hline
\end{tabular}

treatment led to slightly improved growth and larger petals as compared with controls, yet this treatment also had no effect on style length or pollen competitive ability. Thus, it appears that style length and pollen performance were buffered from effects of environmental variation, whereas flower production and petal length were not.

\section{Discussion}

Our results suggest pollen-tube growth rates should influence male reproductive success when large, mixed-donor pollen loads are deposited on stigmas. Not only did we find considerable variation in pollen performance, but the standard donors showed consistent trends in relative siring ability when competing against (1) the same three tester donors, and (2) a randomly chosen group of 14 testers. In the latter case, one standard (\#1) sired $59 \%$ of the seeds within fruits, whereas the other two standards each sired only $43 \%$ (Fig. 2). Given that only three standards were used in this experiment, it is likely that a wider range of pollen performance would be detected if more donors were screened in this way.

Marshall and Folsom (1992) also reported consistent differences in pollen competitive ability in comparisons among four wild radish plants tested on 16 maternal plants. Nonrandom fertilization has been detected in other wild species as well, but in almost all cases the outcome of competition among pollen sources was influenced by interactions with maternal plants and/or too few recipients were used to test for consistent differences among pollen donors (e.g., Bertin 1982, 1986; Marshall and Ellstrand 1986; Lyons et al. 1988; Johnston 1993). Experimental designs that include a broader array of male and female genotypes are needed to determine whether variation in pollen competitive ability varies among individuals in natural populations (Snow 1994).

To interpret the evolutionary significance of nonrandom fertilization, we need to know more about the relative importance of genetic and environmental effects on pollen performance (Stephenson and Bertin 1983; Walsh and Charlesworth 1992). Both types of effects have been reported in other species (Sari-Gorla et al. 1988; Quesada et al. 1991; Stephenson et al. 1992), although heritability of pollen-tube growth rate appears to be low in some species (Snow and Mazer 1988; Havens 1994). In Raphanus raphanistrum and Cucurbita pepo, pollen donors grown in high nutrient soil sired more seeds than did competitors grown in low fertility soil (Young and Stanton 1990; Lau and Stephenson 1993). Herbivore damage to leaves can also affect pollen performance (Quesada et al. 1995), and exposure to low temperatures reduced pollen competitive ability in an alpine wildflower (L. Delph, unpubl. data, 1994). However, some investigators have reported that pollen size, number, and percent germination were not affected by environmental conditions (e.g., Devlin 1988; Pittman and Levin 1989). When this is the case, any genetic effects on pollen performance would be easier to detect.

Salinity and nutrient treatments had no effect on pollen performance in $H$. moscheutos, but we cannot rule out the possibility that other environmental conditions influence this trait. Even if this were the case, though, environmental effects are unlikely to account for the observed variation among pollen donors in the proportion of seeds sired (Figs. 1, 2). In the outdoor experiment, any environmental effects were minimized because the plants were grown in large pots under standardized conditions for 1 to $2 \mathrm{yr}$ prior to this study. Furthermore, these donors often differed in pollen competitive ability despite possible effects of male-female or malemale interactions within the pistil. Therefore, we hypothesize that genetic factors may be responsible for the observed variation in pollen performance.

The existence of variation in pollen competitive ability is somewhat puzzling if one assumes that this variation is heritable and has an impact on male reproductive success. Theory predicts that natural selection should erode genetic variability in fitness-related traits (e.g., Walsh and Charlesworth 1992). Nonetheless, it is possible that mutations, genotypeby-environment interactions, gene flow from populations with relaxed selection pressure (i.e., no pollen competition), or negative genetic correlations could maintain variation in this trait (Snow and Mazer 1988). In a few plant species, there appears to be a positive correlation between pollen-tube growth rate and offspring vigor (see Quesada et al. 1993), but these studies have not specifically addressed the question of whether an individual's average pollen-tube growth rate is correlated with offspring fitness.

Although pollen competitive ability is often cited as a trait that can influence male reproductive success (e.g., Stephenson and Bertin 1983; Lyons et al. 1988; Snow and Spira 1991a,b), this is the first empirical study to screen a large number of co-occurring males for variation in this trait. Pollen-tube competition clearly resulted in nonrandom fertilization in $H$. moscheutos, and the differences we detected among competing pollen donors show that this process can potentially influence an individual's genetic contribution to the next generation. Further research should be aimed at determining whether variation in pollen competitive ability is heritable and whether such variation affects male fitness in the field, where the intensity of competition is certain to be more variable and less stringent than that imposed in hand-pollination experiments (Spira et al. 1996). 


\section{ACKNOWLEDGMENTS}

We thank K. Cochrane, M. Flagg, R. Klips, A. Miller, P. Moran-Palma, A. Ogburn, P. Ray, R. Thomas, J. Tressler, and V. Turman for technical assistance; O. Fincke, R. Klips, D. Marshall, P. Parker, A. Stephenson, and N. Waser provided helpful comments on the manuscript. This research was supported by grants from the National Science Foundation, Ohio State University, and Clemson University.

\section{Literature Cited}

Aizen, M. A., K. B. Search, and D. L. Mulcany. 1990. Amongand within-flower comparisons of pollen-tube growth following self- and cross-pollinations in Dianthus chinensis. Am. J. Bot. 77:671-676.

BERTIN, R. I. 1982. Paternity and fruit production in trumpet creeper (Campsis radicans). 119:694-709.

. 1986. Consequences of mixed pollinations in Campsis radicans. Oecologia 70:1-5.

CAhoon, D. R., AND J. C. Stephenson. 1986. Production, predation, and decomposition in a low salinity Hibiscus marsh. Ecology $67: 1341-1352$.

Carney, S. E., M. B. Cruzan, and M. L. Arnold. 1994. Reproductive interactions between hybridizing irises: Analysis of pollen-tube growth and fertilization success. Am. J. Bot. 81:11691175.

Cruzan, M. B., and S. C. H. BarretT. 1993. Contributions of cryptic incompatibility to the mating system of Eichhornia paniculata (Pontederiaceae). Evolution 47:925-934.

Devlin, B. 1988. The effects of stress on reproductive characters of Lobelia cardinalis. Ecology 69:1716-1720.

GoMENDio, M., AND E. R. S. RoLdan. 1993. Mechanisms of sperm competition: Linking physiology and behavioral ecology. Trends Ecol. Evol. 8:95-100.

HAVENS, L. 1994. Clonal repeatability of in vitro pollen tube growth in Oenothera organensis (Onagraceae). Am. J. Bot. 81: 161-165.

Johnston, M. O. 1993. Tests of two hypotheses concerning pollen competition in a self-compatible, long-styled species (Lobelia cardinalis: Lobeliaceae). Am. J. Bot. 80:763-768.

LAU, T., AND A. G. STEPHENSON. 1993. Effects of soil nitrogen on pollen production: pollen grain size, and pollen performance in Cucurbita pepo (Cucurbitaceae). Am. J. Bot. 80:763-768.

Lyons, E. E., N. M. Waser, M. V. Price, J. Antonovics, and A. F. MOTTEN. 1988. Sources of variation in plant reproductive success and implications for concepts of female choice, malemale competition, and sexual selection. Am. Nat. 134:409-433.

Marshall, D. L., AND N. C. Ellstrand. 1986. Sexual selection in Raphanus sativus: Experimental data on nonrandom fertilization, maternal choice, and consequences of multiple paternity. Am. Nat. 127:446-461.

Marshall, D. L., AND M. W. Folsom. 1991. Mate choice in plants: An anatomical to population perspective. Annu. Rev. Ecol. Syst. $22: 37-64$.

1992. Mechanisms of nonrandom mating in wild radish. Pp. 91-118 in R. Wyatt, ed. Ecology and evolution of plant reproduction. Chapman and Hall, New York.

Mitchell, R. J., AND D. L. MARSHALl. 1995. Effects of pollination method on paternal success in Lesquerella fendleri (Brassicaceae). Am. J. Bot. 82:462-467.

Mulcahy, D. L. 1979. The rise of the angiosperms: A genecological factor. Science 206:20-23.

Pittman, K. E., AND D. A. Levin. 1989. Effects of parental identities and environment on crossing success in Phlox drummondii. Am. J. Bot. 76:409-418.

Quesada, M., C. D. Schlichting, C. D., J. A. Winsor, and A. G. STEPHENSON. 1991. Effects of genotype on pollen performance in Cucurbita pepo. Sex. Plant Reprod. 4:208-214.
Quesada, M., J. A. Winsor, AND A. G. STEPhEnSON. 1992. Effects of pollen competition on progeny performance in a heterozygous cucurbit. Am. Nat. 142:694-706.

Quesada, M., K. Bollman, and A. G. STephenson. 1995. Leaf damage decreases pollen production and hinders pollen performance in Cucurbita texana. Ecology 76:437-443.

Rieseberg, L. H., A. M. Desrochers, AND S. J. Youn. 1995. Interspecific pollen competition as a reproductive barrier between sympatric species of Helianthus (Asteraceae). Am. J. Bot. 82: $515-519$

Sari-Gorla, M., E. M. Otraviano, and D. Faini. 1988. Genetic variability of gametophytic growth rate in maize. Theor. Appl. Genet. 46:289-294.

SAS Procedures SofTware. 1994. SAS Institute, Cary, NC.

SMITH, R. L. 1984. Sperm competition and the evolution of animal mating systems. Academic Press, New York.

SNow, A. A. 1986. Pollination dynamics of Epilobium canum (Onagraceae): Consequences for gametophytic selection. Am. J. Bot. 73:139-151.

13.1 1994. Postpollination selection and male fitness in plants. Am. Nat. 144:S69-S83.

Snow, A. A., AND P. O. Lewis. 1993. Reproductive traits and male fertility in plants: Empirical approaches. Annu. Rev. Ecol. Syst. 24:331-351.

SNow, A. A., AND S. J. MAZER. 1988. Gametophytic selection in Raphanus raphanistrum: A test for heritable variation in pollen competitive ability. Evolution 42:1065-1075.

SNow, A. A., AND T. P. SPIRA. 1991a. Pollen vigor and the potential for sexual selection in plants. Nature 352:796-797.

. 1991b. Differential pollen-tube growth rates and nonrandom fertilization in Hibiscus moscheutos (Malvaceae). Am. J. Bot. 78:1419-1426.

- 1992. Germination as a component of pollen competitive ability in Hibiscus moscheutos. Pp. 388-392 in E. Ottaviano, D. L. Muclahy, and G. Bergamini-Mulcahy, eds. Angiosperm pollen and ovules. Springer Verlag, New York.

1993. Individual variation in the vigor of self-pollen and selfed progeny in Hibiscus moscheutos Malvaceae). Am. J. Bot. $80: 160-164$.

SNow, A. A., T. P. SPIRA, R. Simpson, AND R. A. KLIPS. 1995. The ecology of geitonogamous pollination. Pp. 191-216 in D. L. Lloyd and S. C. H. Barrett, eds. Floral biology. Chapman Hall, New York.

SPIRA, T. P. 1989. Reproductive biology of Hibiscus moscheutos. Pp. 247-255 in J. H. Bock and Y. B. Linhart, eds. The evolutionary ecology of plants. Westview, Boulder, $\mathrm{CO}$.

Spira, T. P., A. A. Snow, D. F. Whigham, AND J. L. Leak. 1992. Flower visitation, pollen deposition, and pollen-tube competition in Hibiscus moscheutos (Malvaceae). Am. J. Bot. 79:428-433.

Spira, T. P., A. A. Snow, AND M. N. Puterbaugh. 1996. The timing and effectiveness of sequential pollination in Hibiscus moscheutos. Oecologia 105:230-235.

StePhenson, A. J., AND R. I. Bertin. 1983. Male competition, female choice, and sexual selection in plants. Pp. 110-149 in L. Real, ed. Pollination biology. Academic Press, New York.

Stephenson, A. G., T. C. LaU, M. Quesada, and J. A. Winsor. 1992. Factors that affect pollen performance. Pp. 119-136 in R. Wyatt, ed. Ecology and evolution of plant reproduction. Chapman and Hall, New York.

WALSh, N. E., AND D. Charlesworth. 1992. Evolutionary interpretation of differences in pollen tube growth rates. Q. Rev. Biol. 67:19-37.

WASER, N. M., AND M. V. PrICE. 1991. Outcrossing distance effects in Delphinium nelsonii: Pollen loads, pollen tubes, and seed set. Ecology 72:171-180.

Young, H. J., AND M. L. Stanton. 1990. Influence of environmental quality on pollen competitive ability in wild radish. Science 248:1631-1633. 